University of Nebraska - Lincoln

DigitalCommons@University of Nebraska - Lincoln

Papers in Natural Resources

Natural Resources, School of

2015

How climate change has affected the spatiotemporal patterns of precipitation and temperature at various time scales in North Korea

\author{
Won-Ho Nam \\ National Drought Mitigation Center, School of Natural Resources, University of Nebraska-Lincoln \\ Eun-Mi Hong \\ USDA-ARS Environmental Microbial \& Food Safety Laboratory, Beltsville Agricultural Research Center \\ Guillermo A. Baigorria \\ University of Nebraska-Lincoln, gbaigorria@unl.edu
}

Follow this and additional works at: http://digitalcommons.unl.edu/natrespapers

Part of the Environmental Sciences Commons, and the Life Sciences Commons

Nam, Won-Ho; Hong, Eun-Mi; and Baigorria, Guillermo A., "How climate change has affected the spatio-temporal patterns of precipitation and temperature at various time scales in North Korea" (2015). Papers in Natural Resources. 493.

http://digitalcommons.unl.edu/natrespapers/493

This Article is brought to you for free and open access by the Natural Resources, School of at DigitalCommons@University of Nebraska - Lincoln. It has been accepted for inclusion in Papers in Natural Resources by an authorized administrator of DigitalCommons@University of Nebraska - Lincoln. 


\title{
How climate change has affected the spatio-temporal patterns of precipitation and temperature at various time scales in North Korea
}

\author{
Won-Ho Nam, ${ }^{\mathrm{a}}$ Eun-Mi Hong ${ }^{\mathrm{b}}$ and Guillermo A. Baigorria ${ }^{\mathrm{c} *}$ \\ a National Drought Mitigation Center, School of Natural Resources, University of Nebraska-Lincoln, NE, USA \\ ${ }^{\mathrm{b}}$ USDA-ARS Environmental Microbial \& Food Safety Laboratory, Beltsville Agricultural Research Center, MD, USA \\ c School of Natural Resources \& Department of Agronomy and Horticulture, University of Nebraska-Lincoln, NE, USA
}

\begin{abstract}
Detecting changes in the spatio-temporal patterns of temperature and precipitation is a prerequisite for developing effective adaptation options and strategies for the future. An effective method for assessing climate change and for providing information to decision makers and stakeholders is needed to implement appropriate adaptation strategies. The objective of this study was to determine whether climate change has caused spatio-temporal changes in meteorological elements in North Korea. We delineated the spatio-temporal patterns of temperature and precipitation caused by climate change in specific time periods based on statistically significant differences using a statistically robust method. Historical weather data from 27 meteorological stations over a 30-year period (1981-2010) were used. The results demonstrated that statistically significant changes occurred over the 30 years. The temporal trends in the maximum and minimum temperatures were highly significantly different in the western agricultural regions and central/southwest urban regions during 1996-2010 compared with 1981-1995. The precipitation amounts were significantly different in the southeast regions (around the coast). The numbers of precipitation events were significantly different for portions of the northern and northeast areas near the mountains. Additionally, statistically significant differences in the spatial structures of the temperature and precipitation were found at different time scales. The significant differences were not uniform in each season/month. Therefore, significant differences occurred in the meteorological elements, and particular locations and urbanized areas were affected by global warming. However, the temporal trends and spatial structures of each meteorological element were not equally modified; the meteorological changes occurred locally as a result of the changing climate.
\end{abstract}

KEY WORDS climate change; spatial structure; correlation matrix; precipitation; temperature; North Korea

Received 22 January 2015; Revised 18 April 2015; Accepted 20 April 2015

\section{Introduction}

Climate change may have significant consequences for temperature and precipitation patterns, including increased climate variability (Hansen et al., 2010). The Intergovernmental Panel on Climate Change (IPCC) stated that climate hazards, including changes in precipitation cycles, reduced crop yields due to changing local temperature regimes, and extreme weather events, are likely to decrease the food security of vulnerable populations (Intergovernmental Panel on Climate Change (IPCC), 2013). Investigations in the form of trend analyses of meteorological observations have been conducted worldwide in recent years with remarkable results (Diaz et al., 2011; Anisimov et al., 2013; Duncan et al., 2013; Shi et al., 2014). However, climate changes will not be homogeneous or uniform globally; substantial differences in temperature and precipitation trends at the regional level will occur

\footnotetext{
* Correspondence to: G. A. Baigorria, School of Natural Resources \& Department of Agronomy and Horticulture, University of Nebraska-Lincoln, 823 Hardin Hall, 3310 Holdrege Street, Lincoln, NE 68583, USA. E-mail: gbaigorria@unl.edu
}

(Reiter et al., 2012). Using precise measurements of climatic parameters at discrete weather stations, it is possible to determine the intensity of regional climate change (Portmann et al., 2008; Reiter et al., 2012). A more reliable measure of changes in the global annual temperature and precipitation is to compare such changes at regional scales with recently observed climate trends. Therefore, an effective method for detecting climate change is needed to understand potential climate risks and to allow decision makers and stakeholders to implement appropriate adaptation strategies using detailed information.

The climate change impacts on temperature and precipitation can be separated into temporal and spatial trends at regional scales (Penalba and Robledo, 2010; Raziei et al., 2014; Nam et al., 2015). A description of regional climate change requires an exploration of the correlated variations across multiple dimensions, i.e. space (geographical variations) and time (the period over which a change is considered) (Baigorria and Jones, 2010). To understand the spatio-temporal trends in climate variability, comprehensive environmental assessments at regional scales are fundamental (Baigorria et al., 2007). It is also necessary 
to determine the statistical significance of the correlation of recently observed interdecadal climate changes (Stephenson, 1997; Coelho et al., 2008).

The climate of North Korea exhibits considerable natural annual and decadal variability, including natural disasters. The types of weather that triggered the drought of the 1990s are increasing in frequency and intensity (Habib, 2008). Trends in temperature and precipitation observations recorded over the last century suggest that the country's climate is changing. These changes include a long-term warming trend interspersed with more frequent extreme temperature events and variations in the timing, frequency, and volume of precipitation. A number of studies have shown evidence of significant changes in climate variables by analysing historical data trends in North Korea. For example, the observed annual mean temperature warmed at a rate of $1.9^{\circ} \mathrm{C}$ during $1918-2000$ (Habib, 2010). Food and Agriculture Organization of the United Nations (FAO) and World Food Programme (WFP) (2013) reported that the increase in the annual mean temperature was approximately $0.38^{\circ} \mathrm{C}$ per decade over the latter part of the century (1971-2006). There has been an increase in the frequency of heavy rain events, which contribute to severe floods (Democratic People's Republic of Korea (DPRK), 2012). North Korea has agricultural productivity problems independent of climate vulnerability due to the small arable land base and meteorological changes. Therefore, the spatio-temporal distribution of meteorological elements should first be estimated. In the case of North Korea, meteorological data and land use data have not been officially released by the North Korean government, and the country participates in very limited information exchange with other countries. Thus, the spatio-temporal changes in temperature and precipitation have not received much attention. Additional literature on climate changes in North Korea is needed to assess the climate change impacts on the already low crop production.

This study focuses on changes in the spatio-temporal trends in meteorological elements and climate change to provide a quantitative understanding of climatic changes using observations over a 30-year period (1981-2010) at 27 meteorological stations in North Korea. Climate change has already affected the spatio-temporal patterns of precipitation and temperature, but where and when the climate change began is unknown. The objectives are to (1) detect and quantify whether temporal changes in precipitation and temperature occurred at annual or monthly time scales and (2) quantify the spatial correlations of meteorological elements among the weather stations. This study provides baseline information on the long-term spatio-temporal variations in the climate.

\section{Materials and methods}

\subsection{Study area}

The Korean Peninsula is located between China and Japan in East Asia $\left(35^{\circ} 50 \mathrm{~N}, 127^{\circ} 00 \mathrm{~W}\right)$; it is bordered by the Yellow Sea to the west and the South and East Korea Seas to the south and east, respectively. The northern-most point of the peninsula is located on the Chinese border at approximately $43^{\circ} \mathrm{N}$. North Korea is located in the northern zone of temperate Asia, and it has a mild climate with four distinct seasons. The seasonal monsoon pattern results in a wet summer and dry spring. The climate is influenced by continental Asia and the surrounding oceans; thus, the climate is typically cold and dry in winter with northerly or northwesterly winds and humid in summer, when heavy rain is induced by the warm southerly or southeasterly winds. The annual average temperature is $9^{\circ} \mathrm{C}$, with averages of $24^{\circ} \mathrm{C}$ in summer (June-August) and $-5.5^{\circ} \mathrm{C}$ in winter (November-February). The annual precipitation is between approximately 1000 and $1200 \mathrm{~mm}$, and it somewhat varies by region. The amount of precipitation is large compared with the $840 \mathrm{~mm}$ mean annual precipitation globally (Korea Meteorological Administration (KMA), 2010). Under these climatic conditions, 50-60\% of the total annual precipitation occurs in July and August, whereas the rainfall in winter is sparse. These meteorological conditions significantly impact the national economy, particularly the agricultural sector (Korea Rural Economic Institute (KREI), 1996; Ireson, 2006).

North Korea is primarily mountainous (approximately $70 \%$ of the land area); thus, suitable land for cultivation is limited. Because of its complex mountainous terrain, the climate variability in North Korea is spatially and temporally complex (Korea Meteorological Administration (KMA), 2010). Agriculture is mostly located in the southwest and east regions dominated by rice paddies and upland terrain. Two thirds of the arable land is found in the four western provinces (North Pyongan, South Pyongan, North Hwanghae, and South Hwanghae), while the three provinces along the Yellow Sea contain $60 \%$ of the nation's paddy fields (KREI, 1996). One fourth of the arable land is contained in the three provinces of the eastern region near the coast (North Hamgyong, South Hamgyong, and Kangwon). The southwest regions (Hwanghaenam-do) are broadly representative of the cultivation areas of North Korea, with the nation's largest paddy fields. The $3300 \mathrm{~km}^{2}$ agricultural area accounts for approximately $17 \%$ of the entire cultivation area of North Korea, and paddy rice cultivation areas account for approximately $26 \%\left(1500 \mathrm{~km}^{2}\right)$ of the total paddy area (Jang et al., 2007). Figure 1 shows the spatial distribution of weather stations and a land cover map obtained from the National Academy of Agricultural Science (NAAS) of South Korea.

\subsection{Meteorological data}

Meteorological data from 27 weather stations in North Korea were obtained from the Korea Meteorological Administration (KMA). The KMA provides climate data from North Korea through the Global Telecommunication System (GTS) network of the World Meteorological Organization (WMO) Information System (WIS). The historical data period covers 30 years (1981-2010). Four variables were used: maximum temperature $\left(T_{\mathrm{X}}\right)$, minimum temperature $\left(T_{\mathrm{I}}\right)$, precipitation amount $\left(P_{\mathrm{P}}\right)$, and 


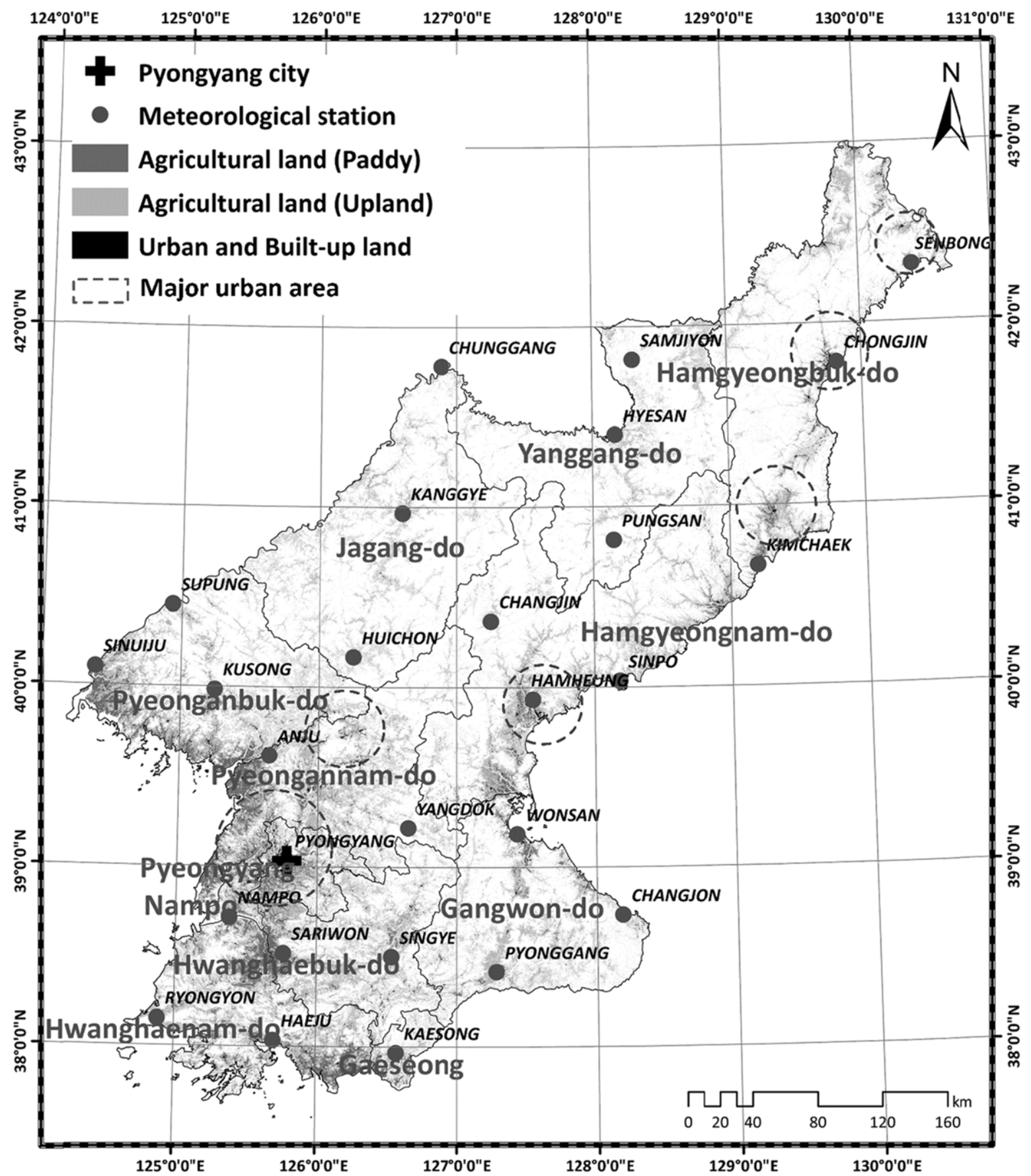

Figure 1. Spatial distribution of the weather stations and land cover map (National Academy of Agricultural Science from South Korea).

number of precipitation events $\left(R_{\mathrm{N}}\right)$. Defining a time scale is important because the meteorological data and climate change impacts may change over time (Fussel and Klein, 2006). The 30-year historical record was divided into three groups. Group I was divided into two sub-periods of 15 years (1981-1995 and 1996-2010). Group II was divided into three sub-periods of 10 years (1981-1990, 1991-2000, and 2001-2010). Finally, group III was divided into six sub-periods of 5 years (1981-1985, 1986-1990, 1991-1995, 1996-2000, 2001-2005, and 2006-2010). The annual and monthly time steps for each group were analysed.

\subsection{Spatial patterns}

The spatial patterns of the seasonal precipitation and temperature were determined by means of statistical distances based on Pearson's correlation coefficient. When spatial analysis is required, it is important to generate spatial correlations between weather stations and monthly statistics for each weather station (Baigorria and Jones, 2010). The spatial patterns were measured by analysing the monthly correlation matrices calculated from the daily observations. To determine the potential changes in the spatial patterns of $T_{\mathrm{X}}, T_{\mathrm{I}}, P_{\mathrm{P}}$ and $R_{\mathrm{N}}$, the spatial patterns over various periods were compared. The daily precipitation 
and temperature data from the periods were grouped into monthly subsets. Each subset, containing daily $T_{\mathrm{X}}, T_{\mathrm{I}}, P_{\mathrm{P}}$, and $R_{\mathrm{N}}$, was used to calculate the correlation between all pairs of weather stations. To avoid overestimating the correlation of the precipitation, only days with rainfall events at both weather stations were used. Pearson's correlation coefficients were calculated using the following equation:

$$
\rho_{i j}=\frac{\frac{1}{n} \sum\left(x_{i}-\mu_{i}\right)\left(x_{j}-\mu_{j}\right)}{\sigma_{i} \sigma_{j}}
$$

where $i, j$ are the weather stations; $x_{i}, x_{j}$ are the daily observed meteorological elements at weather stations $i$ and $j ; \mu_{i}, \mu_{j}$ are the mean values; $\sigma_{i}, \sigma_{j}$ are the standard deviations of each meteorological element; $n$ is the number of observations; and $\rho_{i j}$ are Pearson's correlation coefficients between weather stations $i$ and $j$. Equation (1) was applied to $T_{\mathrm{X}}, T_{\mathrm{I}}, P_{\mathrm{P}}$, and $R_{\mathrm{N}}$ at monthly and annual time scales and different periods to produce correlation matrices of $[27 \times 27]$. To visualize the spatial variability in $\rho_{i j}$ of weather stations $(i)$ and $(j), \rho_{i j}$ was assigned the value of 1.0. The selected weather station was Pyongyang City $\left(39^{\circ} 2 \mathrm{~N}, 125^{\circ} 47 \mathrm{~S}\right.$, and an altitude of $\left.38 \mathrm{~m}\right)$. Values of $\rho_{i j}$ were assigned to the geographical coordinates of the remaining weather stations. Finally, the spatial correlation data were interpolated using inverse-distance weighting (IDW). The spatial patterns are presented for February and July.

\subsection{Statistical analysis}

Statistical analyses were performed to (1) detect periods and areas in which the annual and monthly mean and variance of the meteorological elements were significantly different and (2) compare the monthly correlation matrices of each meteorological element among the periods. The periods within each group were statistically compared through an analysis of variance $F$-test statistic (ANOVA $F$-test statistic). The ANOVA $F$-test is designed for situations in which a significant value and difference are found among the means and variance of more than two groups (between and within groups) by assuming equal variances or normal distributions. The variances were examined for homogeneity. Levene's (1960) is an inferential statistic used to assess the equality of variances in different samples. Levene's test (at the 5\% probability level of significance) was applied to the homogeneity in the variances of each parameter between groups.

In this paper, a trend is considered statistically significant if it is significant at the $5 \%$ probability level (at minimum). The ANOVA $F$-test was applied to detect significantly different periods of meteorological elements (i.e. temporal trends) and to detect significant differences in the correlation matrices for meteorological elements (i.e. spatial trends) due to climate change. Analyses were performed individually at each of the 27 weather stations. The probability ( $p$-value) that the $F$-test statistic was at least as large as the observed $F$-value was assessed using the $F$-distribution table $(\alpha=0.01$ and $\alpha=0.05)$. After the $p$-values were calculated for all of the weather stations, the stations were interpolated to obtain probability maps of the significant differences. Each map showed areas where statistically significant differences in the annual and monthly meteorological elements were found in at least one of the periods within each group.

When differences between groups occurred, a post hoc test was conducted to identify which group differs from the others. Because some areas showed significant differences in at least one period within each group, the next step was to determine in which periods these differences occurred. Duncan's multiple range test was applied to the annual and monthly time steps of each period of groups II and III for all weather stations. Because group I was divided into two periods only, Duncan's multiple range test was not necessary. The results were interpolated to produce annual and monthly maps for each meteorological element. Each map compared the most recent periods (2001-2010 in group II and 2006-2010 in group III) with one of the remaining periods. The interpolation method used was IDW with a grid cell size of $500 \mathrm{~m} \times 500 \mathrm{~m}$, a minimum of three neighbouring points, and a maximum of four neighbouring points; the distance was taken to the fifth power. The interpolation parameters were selected after a trial and error iterative method that attempted to replicate a sample of manually drawn isolines.

\section{Results and discussion}

\subsection{Determining the occurrence of annual changes}

Figure 2 maps the spatial distribution of the $p$-values as annual statistical indicators of each meteorological element that was significantly different within the group in each period. The areas in dark grey and medium grey represent significant differences at the 0.01 and 0.05 probability levels, respectively. The white areas have no significant differences in the analysed meteorological elements at any time period. $T_{\mathrm{X}}$ shows the significant differences in small southwest and northeast regions (coastal areas) in all groups. Significant differences in $T_{\mathrm{I}}$ were found over the entire region in groups I and II and over the central regions in group III. The $T_{\mathrm{I}}$ maps showed highly significant differences in the temporal trends in the west (agricultural area) and central/southwest (urban area of Pyongyang City) in all groups. $P_{\mathrm{P}}$ shows significant differences over small areas in the southeast in group II. However, areas with significant differences in $P_{\mathrm{P}}$ were widespread in a northeast-southeast swath near the coast in group III. In the case of $R_{\mathrm{N}}$, areas with significant differences for all groups were found in the northern mountains.

The results showed significant differences for each meteorological element. In the case of group I, the results showed that $T_{\mathrm{I}}$ in the past 15 years (1996-2010) was significantly different over the entire area compared with the previous 15 years $(1981-1995) . R_{\mathrm{N}}$ over the past 15 years was significantly different in the north compared with the previous 15 years. However, $T_{\mathrm{X}}$ and $P_{\mathrm{P}}$ only showed changes in coastal areas. In the case of group II, the results generally showed similar tendencies when compared with 


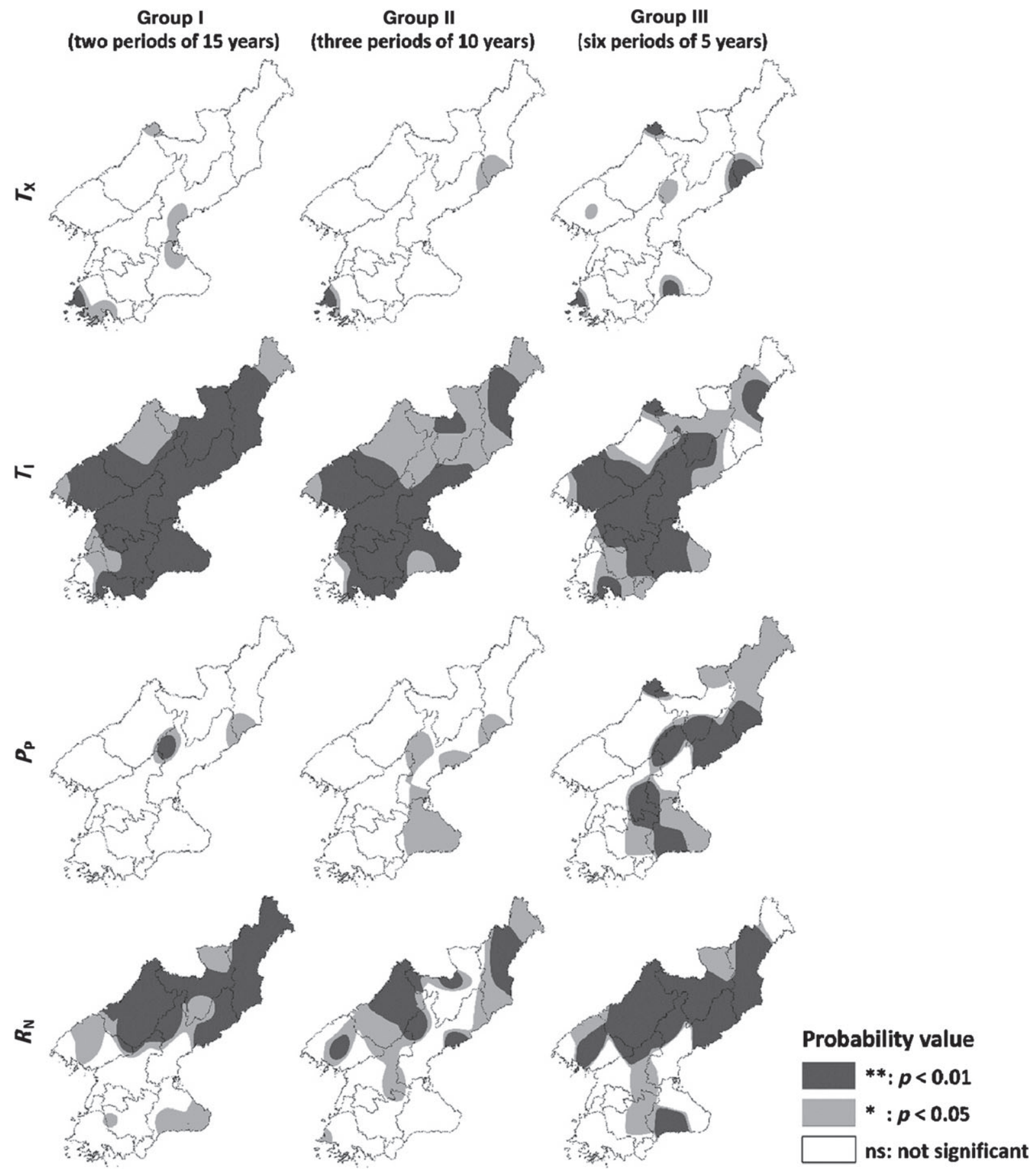

Figure 2. Spatial distribution of $p$-values for annual meteorological elements $\left(T_{\mathrm{X}}=\right.$ maximum temperature, $T_{\mathrm{I}}=$ minimum temperature, $P_{\mathrm{P}}=$ precipitation, $R_{\mathrm{N}}=$ number of rainfall events) with the $F$-test statistics from ANOVA for different groups.

group I. In the case of group III, $P_{\mathrm{P}}$ was significantly different in northeast and southeast areas near coasts. These results indicate that the detected changes in $P_{\mathrm{P}}$ are a function of the location's proximity to the coast (Groisman et al., 1999).

3.2. Determining the timing and locations of possible annual changes

After identifying these significant differences, Duncan's multiple range test was used to determine whether each 10 -year and 5-year period differed from the most recent period (e.g. 2001-2010 for group II and 2006-2010 for group III). Figure 3 maps the spatial distribution of the $p$-values of the annual statistical indicators of each meteorological element that was significantly different in a 10-year period compared with the latest period (2001-2010). The results for $T_{\mathrm{X}}$ show small areas in which significant differences occurred in the first decade (1981-1990). Significant differences were found in the southeast (coastal areas). The maps of $T_{\mathrm{I}}$ indicate that the entire area experienced highly significant differences during the first decade. The $T_{\mathrm{I}}$ change affected a large area, 

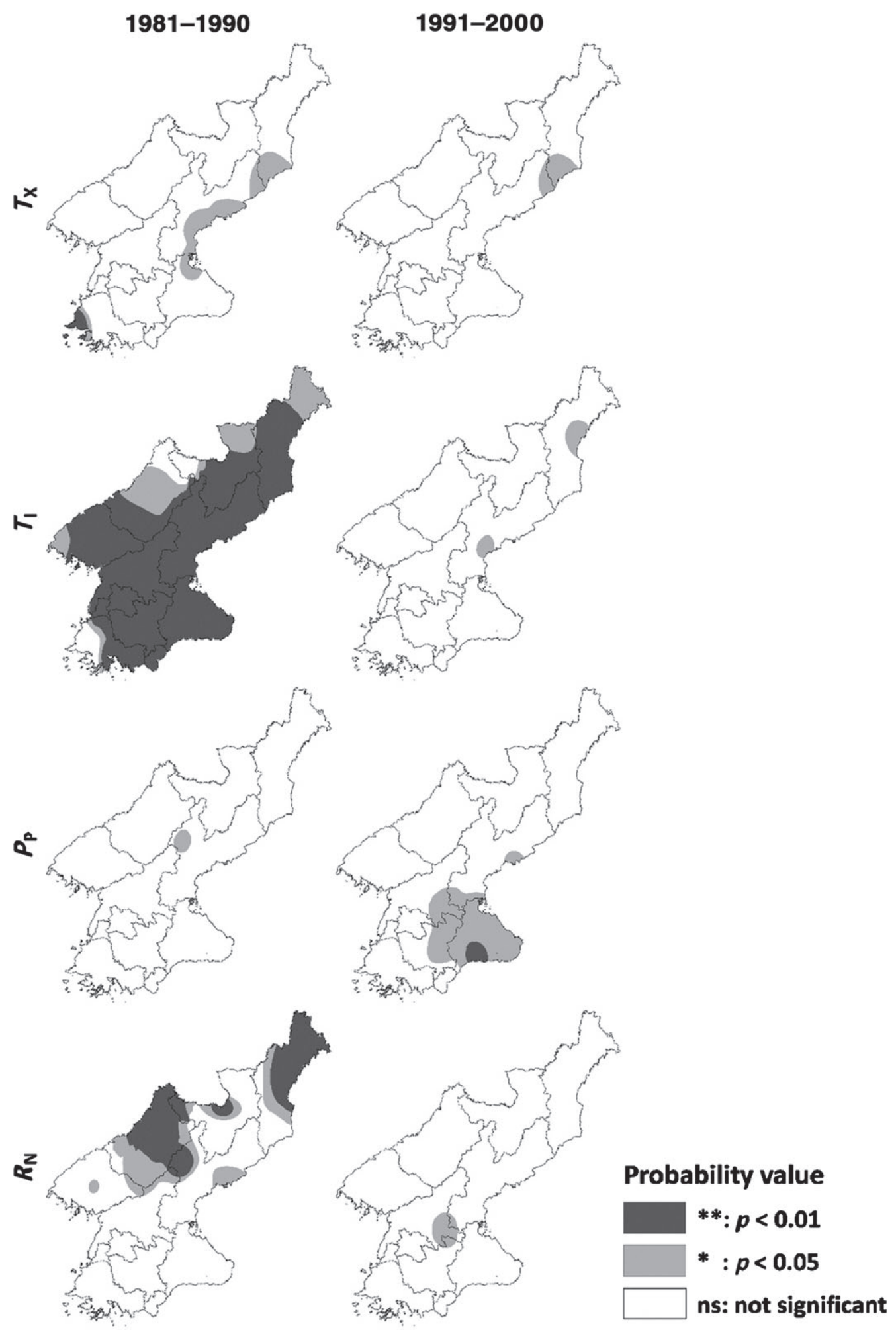

Figure 3. Maps of Duncan's multiple range test $p$-values for annual meteorological elements $\left(T_{\mathrm{X}}=\right.$ maximum temperature, $T_{\mathrm{I}}=$ minimum temperature, $P_{\mathrm{P}}=$ precipitation, $R_{\mathrm{N}}=$ number of rainfall events) in group II (compared with 2001-2010).

with greater significant differences than $T_{\mathrm{X}}$. However, $T_{\mathrm{X}}$ and $T_{\mathrm{I}}$ did not have significant differences in the second decade (1991-2000). $P_{\mathrm{P}}$ was not significantly different during the first decade. The maps of $P_{\mathrm{P}}$ indicate that part of the southeast experienced significant differences during the second decade. In contrast, maps of $R_{\mathrm{N}}$ indicate that parts of the north and northeast experienced significant differences in the first decade.

Figure 4 shows the spatial distribution of the $p$-values of the annual statistical indicators of each meteorological element that was significantly different over the 5-year period compared with the latest period (2006-2010). In 

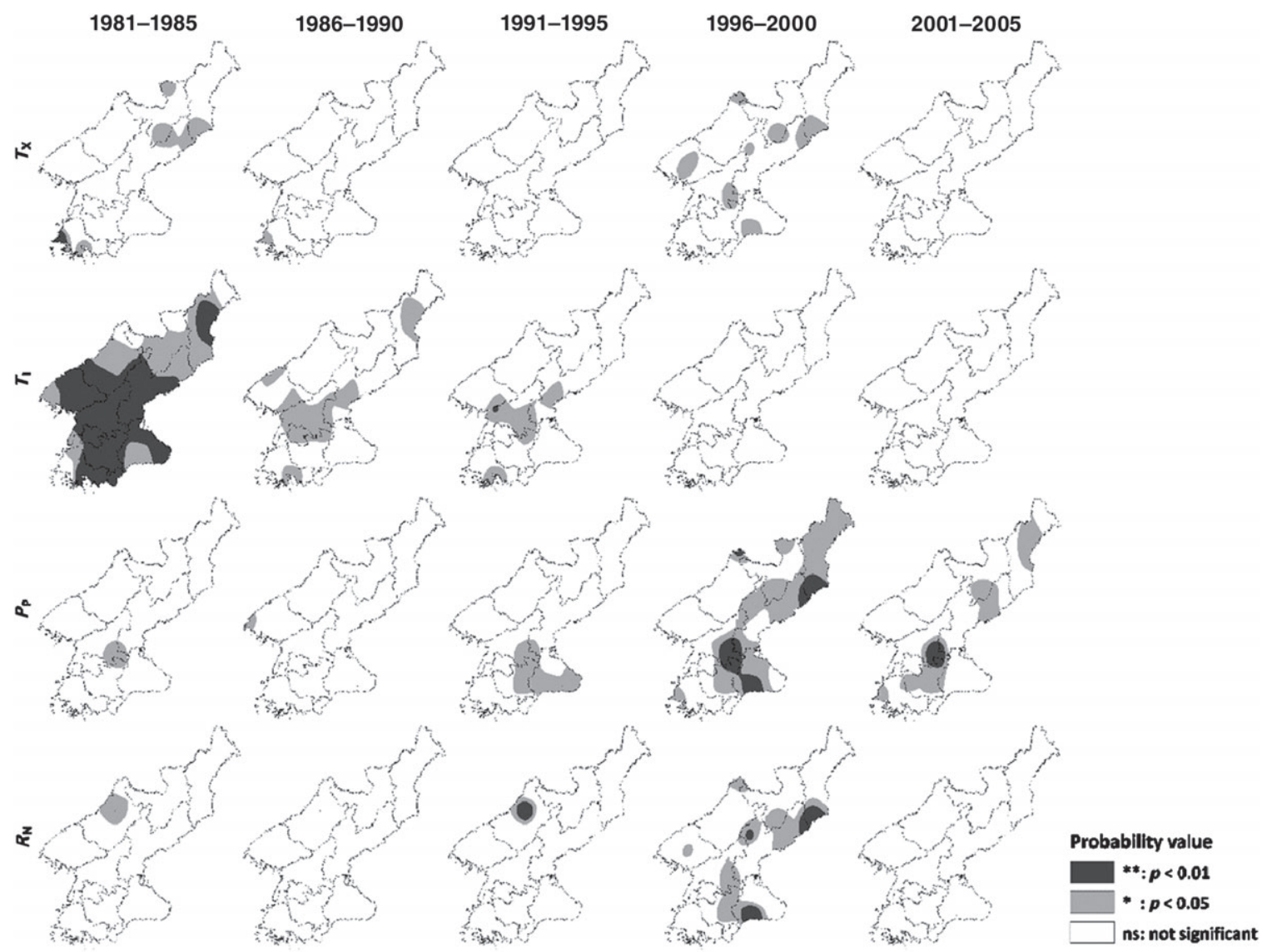

Figure 4. Maps of Duncan's multiple range test $p$-values for annual meteorological elements $\left(T_{\mathrm{X}}=\right.$ maximum temperature, $T_{\mathrm{I}}=$ minimum temperature, $P_{\mathrm{P}}=$ precipitation, $R_{\mathrm{N}}=$ number of rainfall events) in group III (compared with 2006-2010).

the case of $T_{\mathrm{X}}$, significant differences occurred during the first (1981-1985) and fourth (1996-2000) 5-year periods in the northeast near the coast. Maps of $T_{\mathrm{I}}$ indicate that entire areas (except the north) were significantly different during the first 5-year period. Significant differences occurred during the second (1986-1990) and third (1991-1995) 5-year periods in the central region (urban area of Pyongyang City). In the case of $P_{\mathrm{P}}$, significant differences occurred during the third, fourth, and fifth 5-year periods in the central and northeast/southeast regions. Maps of $P_{\mathrm{P}}$ indicate that northeast-southeast areas located near the coast were significantly different during the fourth 5 -year period. $R_{\mathrm{N}}$ was significantly different in parts of the southeast and south during the fourth 5-year period only.

We found different temporal trends for each meteorological element under climate change over the past 30 years. $T_{\mathrm{X}}$ changes were significant over small areas along the coast in the first decade (1981-1990); the changes ended in the second decade (1991-2000). The average increase in $T_{\mathrm{X}}$ for the meteorological stations where significant differences occurred in the first decade was $0.3^{\circ} \mathrm{C}$ compared with the most recent period (2001-2010). Although the intensity of the change over time decreased, $T_{\mathrm{I}}$ changes were continuously significant until the second decade (1991-1995). The average increase in $T_{\mathrm{I}}$ during the first decade was $1.0^{\circ} \mathrm{C}$ compared with the most recent period, in contrast to the uniform increase in the mean temperature of $0.38^{\circ} \mathrm{C}$ per decade reported by FAO and WFP (2013). Changes in $P_{\mathrm{P}}$ were significantly different during the second decade. The average increase in $P_{\mathrm{P}}$ during the second decade was $212 \mathrm{~mm}$ compared with the most recent period. However, DPRK (2012) reported that no statistically significant observable trend occurred in the annual precipitation over 1918-2007. In contrast, changes in $R_{\mathrm{N}}$ were significantly different during the first decade only. The average decrease in $R_{\mathrm{N}}$ during the first decade was 11 days compared with the latest period.

Therefore, climate change was not equally manifested in each meteorological element, depending on the spatial and temporal patterns. The results of $T_{\mathrm{I}}$ provide evidence of a statistically significant increase over the entire area during the first decade compared with $T_{\mathrm{X}}$ due to climate change. $P_{\mathrm{P}}$ significantly increased in coastal areas during the second decade; however, $R_{\mathrm{N}}$ decreased during the first decade in coastal areas.

\subsection{Determining the occurrence of monthly changes}

The $p$-values of the monthly statistical indicators of each meteorological element indicate that significant within-group differences occurred between the periods. $T_{\mathrm{X}}$ in the southwest (agricultural areas) experienced significant differences in September (group I). The $T_{\mathrm{I}}$ change indicated that part of the southwest and central areas from March to June had significantly different temporal trends, 


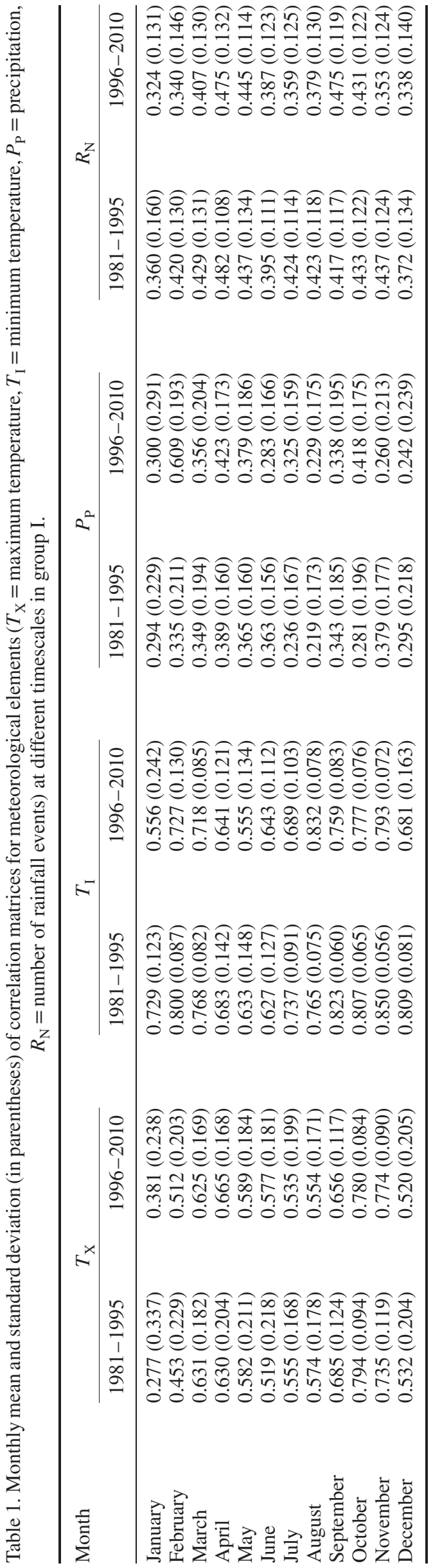

Table 2. Duncan's multiple range tests of correlation matrices for meteorological elements $\left(T_{\mathrm{X}}=\right.$ maximum temperature, $T_{\mathrm{I}}=$ minimum temperature, $P_{\mathrm{P}}=$ precipitation, $R_{\mathrm{N}}=$ number of rainfall events) between different timescales in group I.

\begin{tabular}{|c|c|c|c|c|}
\hline \multirow[t]{2}{*}{ Month } & \multicolumn{4}{|c|}{ (1981-1995) versus (1996-2010) } \\
\hline & $T_{\mathrm{X}}$ & $T_{\mathrm{I}}$ & $P_{\mathrm{P}}$ & $R_{\mathrm{N}}$ \\
\hline January & $* *$ & $* *$ & ns & $*$ \\
\hline February & $* *$ & $* *$ & $* *$ & $* *$ \\
\hline March & ns & $* *$ & ns & ns \\
\hline April & $*$ & $* *$ & ns & ns \\
\hline May & ns & $* *$ & ns & ns \\
\hline June & $* *$ & ns & $* *$ & ns \\
\hline July & ns & $* *$ & $* *$ & $* *$ \\
\hline August & ns & $* *$ & ns & $* *$ \\
\hline September & $*$ & $* *$ & ns & $* *$ \\
\hline October & ns & $* *$ & $* *$ & ns \\
\hline November & $* *$ & $* *$ & $* *$ & $* *$ \\
\hline December & $\mathrm{ns}$ & $* *$ & $*$ & $*$ \\
\hline
\end{tabular}

ns, not statistically significant.

*Significant at the 0.05 probability level, **significant at the 0.01 probability level.

mainly around urban areas. Additionally, all significantly different $T_{\mathrm{I}}$ values occurred in September and October. Significantly different $P_{\mathrm{P}}$ occurred in June in small central regions. However, highly significant changes in $R_{\mathrm{N}}$ were found in northern areas from May to September, mainly around mountains.

In the case of groups II and III, the temporal trends were generally similar per season and region compared with group I. Significant differences in $T_{\mathrm{X}}$ were found in the northeast and southwest during September (groups II and III). $T_{\mathrm{I}}$ in the central region was highly significantly different from May to June, September, and December to January around urban areas (groups II and III). Additionally, agricultural areas of the midwest and southwest during May, June, and September experienced significant differences (groups II and III). Significant differences in $P_{\mathrm{P}}$ were only found in the southeast during July in group II. Significant differences in $R_{\mathrm{N}}$ were found in the north during June and July in groups II and III.

The temporal trends in the monthly temperatures were significantly different in May-June (summer) and September-October (fall), which are transitional months between spring and winter in all groups. The monthly precipitation amount did not significantly change over time; however, the monthly number of precipitation events had highly significant differences (decreases) in July and September. Fewer rainfall events per month with the same total amount of precipitation indicate an increase in the intensity of rainfall events in the region.

3.4. Determining the timing and locations of monthly changes

Regarding the results of Duncan's multiple range tests of monthly statistical indicators for all of the meteorological stations in group II, there were significant differences for the 10-year period compared with the most recent period (2001-2010). The average increase in $T_{\mathrm{X}}$ 


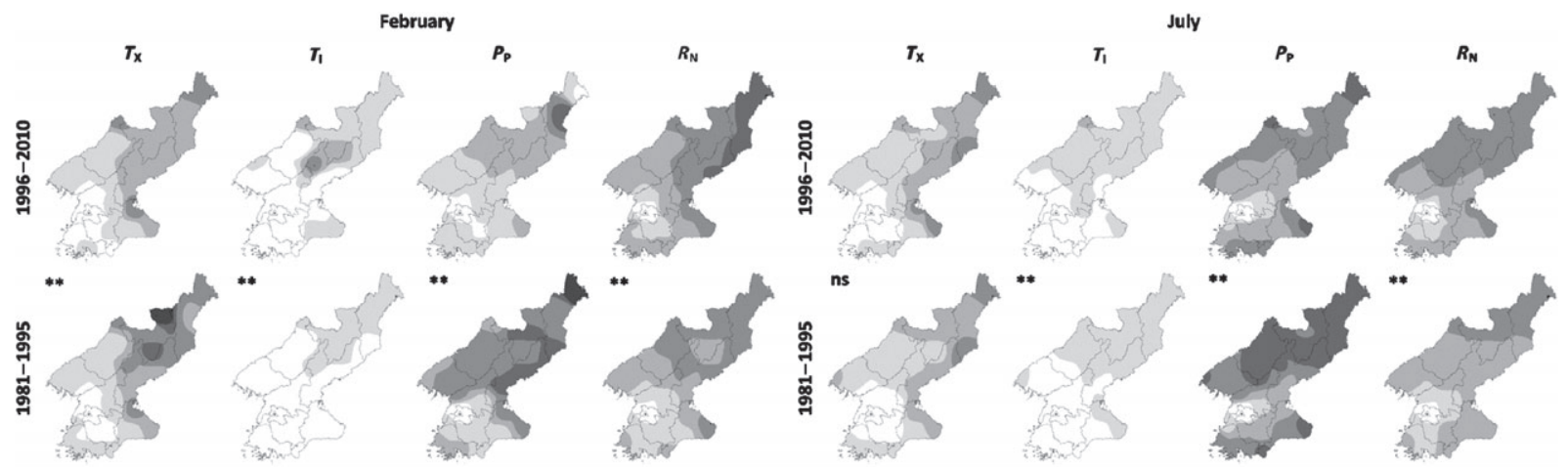

Figure 5. Correlative spatial variability of meteorological elements $\left(T_{\mathrm{X}}=\right.$ maximum temperature, $T_{\mathrm{I}}=$ minimum temperature, $P_{\mathrm{P}}=$ precipitation, $R_{\mathrm{N}}=$ number of rainfall events) at Pyongyang for February and July compared with each period of group I. The level of statistical significance $(*=0.05 ; * *=0.01 ; \mathrm{ns}=$ no significance) after comparing the latest period (1996-2010) is shown. The white represents positive correlations, black represents negative correlations, and grey represents no significant correlations.

for all the meteorological stations with significant differences during the first decade was $0.9^{\circ} \mathrm{C}$ in September compared with the most recent decade. The $T_{\mathrm{I}}$ change showed highly significant differences in May-June and September-October during the first decade. Significant differences in $T_{\mathrm{I}}$ were found across the entire country in June. The average increases in $T_{\mathrm{I}}$ for meteorological stations with significant differences in the first decade were $1.0^{\circ} \mathrm{C}$ in May, $1.1{ }^{\circ} \mathrm{C}$ in June, $1.2^{\circ} \mathrm{C}$ in September, and $1.1^{\circ} \mathrm{C}$ in October compared with the latest decade. The changes in $P_{\mathrm{P}}$ were significantly different only in July during the second decade. The average increase in $P_{\mathrm{P}}$ during the second decade was $82 \mathrm{~mm}$ in July compared with the most recent period. In contrast, the changes in $R_{\mathrm{N}}$ were significantly different from May to September during the first decade. The average decrease in $R_{\mathrm{N}}$ during the first decade was 1.5 days from May to September compared with the most recent period.

Regarding the results of Duncan's multiple range tests of monthly statistical indicators of each meteorological element for all of the meteorological stations in group III, there were significant differences for the 5 -year period compared with the most recent period (2006-2010). In the case of $T_{\mathrm{X}}$, significant differences were found in the midwest and southwest regions in January during 1981-1985. Significant differences were also found in the southern regions in September during 1981-2000. $T_{\mathrm{I}}$ changes were found to be significantly different across the entire region in May during 1981-1995. In the southwest, $T_{\mathrm{I}}$ changes were also significantly different in June during 1981-1990 and in September during 1986-1995. In the case of $P_{\mathrm{P}}$ and $R_{\mathrm{N}}$, significant differences were found in the northeast regions in April during 1996-2000.

The temperature results provide evidence of a statistically significant increase from May to June and from September to October during 1981-1995 compared with the most recent period. The precipitation results show significant differences in April and October during 1996-2000. The changes in the temporal trends of temperature and precipitation occurred locally as a consequence of climate change.

\subsection{Spatial correlation changes at different time scales} in group I

Table 1 shows the monthly mean and standard deviation of the $[27 \times 27]$ monthly correlation matrices for all weather stations and each meteorological element at different time scales in group I. According to a comparison of the relative correlation means among the meteorological elements, $T_{\mathrm{X}}$ and $T_{\mathrm{I}}$ showed a higher spatial correlation than $P_{\mathrm{P}}$ and $R_{\mathrm{N}}$. Seasonally, spring and fall showed higher correlation means than summer and winter for $T_{\mathrm{X}}$ and $T_{\mathrm{I}}$.

Between 1981-1995 and 1996-2010, the correlations of $T_{\mathrm{X}}$ from January and June during the most recent period (1996-2010) showed higher spatial correlations compared with the first period (1981-1995); however, the results from July and October showed lower spatial correlations. The correlations of $T_{\mathrm{I}}$ in all months during the most recent period showed lower spatial correlations compared with the first period, except in June and August. The precipitation showed different spatial correlations compared with the temperature. The correlations of $P_{\mathrm{P}}$ in all months during the most recent period showed a higher spatial correlation compared with the first period, except in June, September, and November. The correlations of $R_{\mathrm{N}}$ in all months during the most recent period showed lower spatial correlations compared with the first period; however, the results in May and September showed higher spatial correlations.

After identifying the significant differences, Duncan's multiple range test was used to compare the spatial structures at different time scales, as shown in Table 2. The correlations of $T_{\mathrm{X}}$ in January and February were statistically significant at the probability level of $\alpha=0.01 / 0.05$ between 1981-1995 and 1996-2010. However, there were significant differences in the spatial structure of $T_{\mathrm{I}}$ for almost all months. The correlations of $P_{\mathrm{P}}$ in June-July and October-December were statistically significant, and the correlations of $R_{\mathrm{N}}$ in July-September and November-February were statistically significant. These results demonstrate the changes in statistically significant correlations of temperature and precipitation at different time scales. 
Figure 5 shows the spatial structure of the meteorological variables when one weather station, such as that in Pyongyang City, was selected. The areas shown in white indicate positive correlations at the selected weather station, black represents negative correlations, and grey represents no significant correlations. The level of statistical significance during 1981-1995 compared with 1996-2010 in group I is shown at the top right corner of each map. The top row shows the spatial structure for each variable for February and July during the first period. Row 2 represents the spatial structure during the most recent period. The spatial structures of the temperature and precipitation between 1981-1995 and 1996-2010 were statistically significant for all meteorological variables. The spatial structure of $T_{\mathrm{X}}$ in July was not significantly different compared with 1996-2010. The February maps indicate that a portion of the northeast experienced significant spatial differences in $T_{\mathrm{X}}, P_{\mathrm{P}}$, and $R_{\mathrm{N}}$. The maps of $T_{\mathrm{I}}$ showed a significant difference in some central regions. Spatially, lower positive correlations were found during 1996-2010 than during 1981-1995 in the central regions. The spatial correlations of $P_{\mathrm{P}}$ during 1996-2010 were highly significantly different in parts of the northeast in July compared with 1981-1995. The maps of $P_{\mathrm{P}}$ were also more positively correlated from northeast to southwest during 1996-2010 than during 1981-1995.

3.6. Spatial correlation changes at different time scales in group II

Table 3 shows the monthly mean and standard deviation of the monthly correlation matrices for all weather stations for each meteorological element at different time scales in group II. Over three decades, the correlations of $T_{\mathrm{X}}$ in January, February, and June over the most recent decade (2001-2010) showed continuously higher spatial correlations compared with the first (1981-1990) and second decades (1991-2000). However, the results in May and December over the most recent decade showed lower spatial correlations compared with other months over the second decade. The correlations of $T_{\mathrm{I}}$ in all months during the latest decade showed higher spatial correlations compared with the second decade and lower spatial correlations compared with the first decade, except in February, June, and August. The correlations of $P_{\mathrm{P}}$ from November to January over the latest decade showed lower spatial correlations compared with the first and second decades. The correlations of $R_{\mathrm{N}}$ in April-June and September-October during the most recent decade showed continuously higher spatial correlations compared with the first and second decades. However, the correlations of $R_{\mathrm{N}}$ in July showed continuously lower spatial correlations.

After identifying these significant differences, Duncan's multiple range test was used to compare the spatial structures at different time scales, as shown in Table 4. The correlations of $T_{\mathrm{X}}$ in all months except June were statistically significant at the probability level of $\alpha=0.01 / 0.05$ between the first and last decades. The correlations of $T_{\mathrm{X}}$ from April and July were significantly different between the second

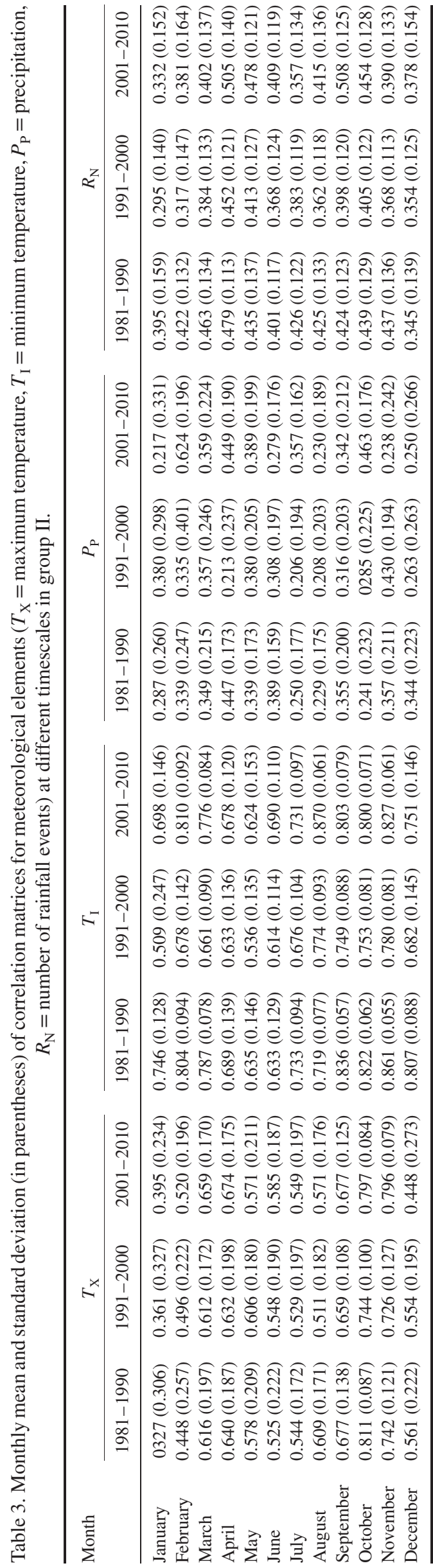


Table 4. Duncan's multiple range tests of correlation matrices for meteorological elements $\left(T_{\mathrm{X}}=\right.$ maximum temperature, $T_{\mathrm{I}}=$ minimum temperature, $P_{\mathrm{P}}=$ precipitation, $R_{\mathrm{N}}=$ number of rainfall events) between different timescales in group II.

\begin{tabular}{|c|c|c|c|c|c|c|c|c|}
\hline \multirow[t]{2}{*}{ Month } & \multicolumn{4}{|c|}{$(1981-1990)$ versus $(2001-2010)$} & \multicolumn{4}{|c|}{ (1991-2000) versus (2001-2010) } \\
\hline & $T_{\mathrm{X}}$ & $T_{\mathrm{I}}$ & $P_{\mathrm{P}}$ & $R_{\mathrm{N}}$ & $\mathrm{T}_{\mathrm{X}}$ & $T_{\mathrm{I}}$ & $P_{\mathrm{P}}$ & $R_{\mathrm{N}}$ \\
\hline January & $* *$ & ns & $* *$ & $* *$ & $* *$ & $* *$ & $* *$ & $*$ \\
\hline February & $* *$ & $* *$ & $*$ & $* *$ & ns & ns & ns & $* *$ \\
\hline March & $* *$ & $* *$ & $* *$ & ns & ns & ns & $* *$ & ns \\
\hline April & $* *$ & $*$ & ns & $* *$ & $* *$ & ns & $* *$ & $* *$ \\
\hline May & $* *$ & ns & $* *$ & $\mathrm{~ns}$ & $*$ & ns & $*$ & $* *$ \\
\hline June & ns & $* *$ & ns & $\mathrm{ns}$ & $* *$ & $* *$ & $*$ & $* *$ \\
\hline July & $* *$ & ns & $* *$ & $* *$ & $*$ & ns & ns & ns \\
\hline August & $* *$ & $*$ & $\mathrm{~ns}$ & $\mathrm{~ns}$ & ns & $* *$ & $* *$ & $* *$ \\
\hline September & $* *$ & ns & $* *$ & ns & ns & $* *$ & ns & $* *$ \\
\hline October & $* *$ & ns & ns & $* *$ & ns & $* *$ & $* *$ & $* *$ \\
\hline November & $* *$ & $* *$ & $* *$ & $* *$ & $* *$ & $* *$ & $* *$ & ns \\
\hline December & $* *$ & $* *$ & ns & ns & $* *$ & $* *$ & $* *$ & ns \\
\hline
\end{tabular}

ns, not statistically significant.

*Significant at the 0.05 probability level, **significant at the 0.01 probability level.
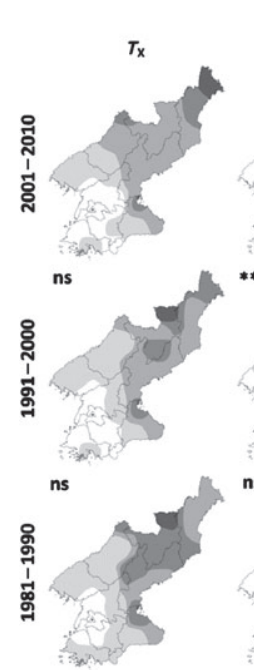

February
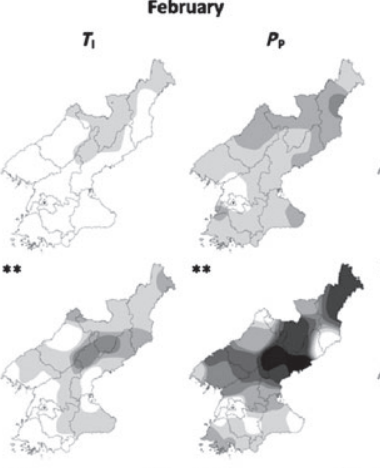
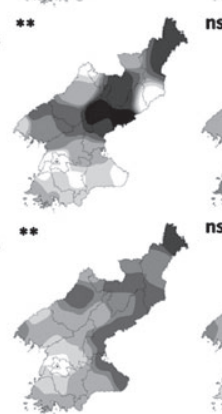
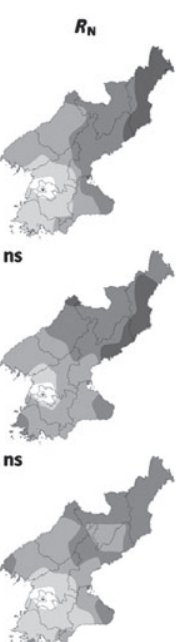
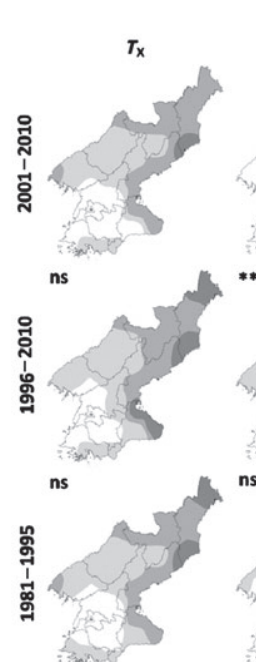

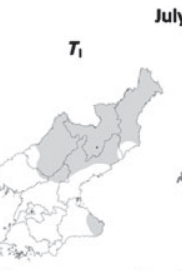

July

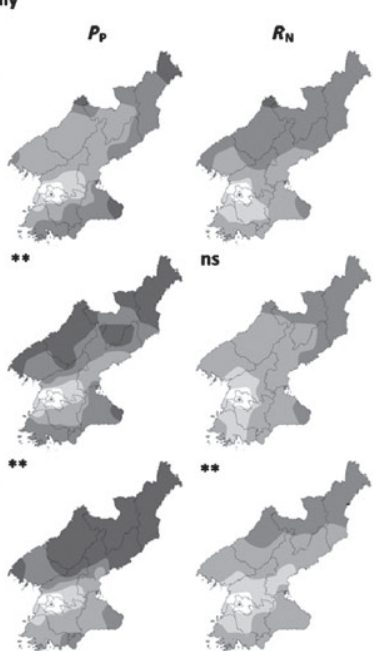

Figure 6. Correlative spatial variability of meteorological elements $\left(T_{\mathrm{X}}=\right.$ maximum temperature, $T_{\mathrm{I}}=$ minimum temperature, $P_{\mathrm{P}}=$ precipitation, $R_{\mathrm{N}}=$ number of rainfall events) at Pyongyang for February and July compared with each period of group II. The level of statistical significance $(*=0.05 ; * *=0.01 ; \mathrm{ns}=$ no significance $)$ after comparing the latest period $(2001-2010)$ is shown. The white represents positive correlations, black represents negative correlations, and grey represents no significant correlations.

decade and latest decade; however, there were significant differences in the spatial structure of $T_{\mathrm{I}}$ from August to January. Additionally, the correlations of $P_{\mathrm{P}}$ in all months except February, July, and September were statistically significant, and the correlations of $R_{\mathrm{N}}$ in April-June and August-October were statistically significant between the second and last decades.

Figure 6 shows the spatial structure of the meteorological variables when one weather station was selected. The level of statistical significance during the first and second decades compared with the most recent decade in group II is shown in the top right corner of each map. The spatial structures of $T_{\mathrm{X}}$ and $R_{\mathrm{N}}$ in February and July were not significantly different compared with the most recent decade. The February and July maps indicated that a portion of the central regions showed significant spatial differences in $T_{\mathrm{I}}$ during the second decade. The spatial correlations of $P_{\mathrm{P}}$ in February and July during the first and second decades showed highly significant differences in the northeast and central regions compared with the most recent decade. There were lower positive and negative spatial correlations in the central regions during the second decade.

\section{Conclusions}

Because temperature and precipitation are an important and key parameters in understanding agricultural crop production, the spatio-temporal patterns of meteorological elements are an important concern which should be investigated. In this study, we identified whether statistically significant changes in the spatio-temporal trends in the maximum and minimum temperatures and precipitation (amount and distribution) at different time scales occurred under climate change in North Korea. The results demonstrated that statistically significant changes 
occurred over 30 years (1981-2010). The temporal trends in the maximum and minimum temperatures were highly significantly different in the western agricultural regions and central/southwest urban regions during 1996-2010 compared with 1981-1995. The precipitation amounts were significantly different in the southeast regions (around the coast). The number of precipitation events indicates that portions of the northern and northeast areas near the mountains showed significant differences. Additionally, statistically significant differences in the spatial structures of temperature and precipitation were found at different time scales. The significant differences were not uniform in each season/month. Therefore, there are significant differences in meteorological elements, and particular locations and urbanized areas were affected by global warming.

Changes in meteorological elements that are affected by climate change should be considered to formulate reasonable policies concerning the future agricultural crop production and water resources. Therefore, this study was successful in providing the significant baseline information on long-term trends in spatio-temporal climate variations that can be used for various agricultural crop management and water resources planning purposes at regional levels in North Korea. Furthermore, these results improve our knowledge about the regional patterns of modern climate change in North Korea, which is likely to hold the fingerprint of the climate change signal. The findings of this study also provides ample information that is expected to obtain insight into regional climatic changes over the past agricultural productivity problems and natural disasters such as drought and flood events in North Korea. Ultimately, we hope this study and our results demonstrate the need and importance of knowledge about the regional meteorological patterns that will inform decision-making processes, adaptive management, and development to minimize the negative impacts of climate change on food production in North Korea.

\section{Acknowledgements}

This research was supported by the Basic Science Research Program through the National Research Foundation of Korea (NRF) and was funded by the Ministry of Education, Science and Technology (2013R1A6A3 A03019009), and it was developed under the auspices of the Robert B. Daugherty Water for Food Institute (WFI), and the CropClimate Initiative. The authors wish to thank one anonymous reviewer and Hi-Ryong Byun for their valuable suggestions regarding the manuscript. The views expressed in this paper are those of the authors and do not necessarily reflect the views of NRF, WFI, or any of its sub-agencies.

\section{References}

Anisimov O, Kokorev V, Zhil'tsova Y. 2013. Temporal and spatial patterns of modern climatic warming: case study of Northern Eurasia. Clim. Change 118: 871-883, doi: 10.1007/s10584-013-0697-4.
Baigorria GA, Jones JW. 2010. GiST: a stochastic model for generating spatially and temporally correlated daily rainfall data. J. Clim. 23: 5990-6008, doi: 10.1175/2010JCLI3537.1.

Baigorria GA, Jones JW, O'Brien JJ. 2007. Understanding rainfall spatial variability in southeast USA at different timescales. Int. J. Climatol. 27: 749-760, doi: 10.1002/joc.1435.

Coelho CAS, Ferro CAT, Stephenson DB, Steinskog DJ. 2008. Methods for exploring spatial and temporal variability of extreme events in climate data. J. Clim. 21: 2072-2092, doi: 10.1175/2007JCLI1781.1.

Democratic People's Republic of Korea (DPRK). 2012. Environment and Climate Change Outlook. Ministry of Land and Environment Protection: Pyongyang.

Diaz HF, Trigo R, Hughes MK, Mann ME, Xoplaki E, Barriopedro D. 2011. Spatial and temporal characteristics of climate in medieval times revisited. Bull. Am. Meteorol. Soc. 92: 1487-1500, doi: 10.1175/BAMS-D-10-05003.1.

Duncan JMA, Dash J, Atkinson PM. 2013. Analysing temporal trends in the Indian summer monsoon and its variability at a fine spatial resolution. Clim. Change 117: 119-131, doi: 10.1007/s10584-012-0537-y.

Food and Agriculture Organization of the United Nations (FAO) and World Food Programme (WFP). 2013. FAO/WFP Crop and Food Security Assessment Mission to the Democratic People's Republic of Korea. Crop and Food Security Assessment Mission (CFSAM), FAO/WFP: Rome.

Fussel HM, Klein RJT. 2006. Climate change vulnerability assessments: an evolution of conceptual thinking. Clim. Change 75: 301-320, doi: 10.1007/s10584-006-0329-3.

Groisman PY, Karl TR, Easterling DR, Knight RW, Jamason PF, Hennessy KJ, Suppiah R, Page CM, Wibig J, Fortuniak K, Razuvaev VN, Douglas A, Førland E, Zhai PM. 1999. Changes in the probability of heavy precipitation: important indicators of climatic change. Clim. Change 42: 243-283, doi: 10.1023/A:1005432803188.

Habib B. 2008. Climate change and the terminal decay of the North Korean regime. In Proceedings of the 3rd Biennial Oceanic Conference on "International Studies", Brisbane, Australia, 2-4 July, 2008.

Habib B. 2010. Climate change and regime perpetuation in North Korea. Asian Surv. 50: 378-401, doi: 10.1525/as.2010.50.2.378.

Hansen J, Ruedy R, Sato M, Lo K. 2010. Global surface temperature change. Rev. Geophys. 48: RG4004, doi: 10.1029/2010RG000345.

Intergovernmental Panel on Climate Change (IPCC). 2013. Climate Change 2013: The Physical Science Basis. Working Group I Contribution to the Fifth Assessment Report of the Intergovernmental Panel on Climate Change. Cambridge University Press: Cambridge, UK and New York, NY.

Ireson R. 2006. Designing food security in North Korea: designing realistic possibilities. In Shorenstein Asia-Pacific Center Working Paper, Shorenstein Asia-Pacific Research Center, Stanford, CA.

Jang MW, Choi JY, Lee JJ. 2007. A spatial reasoning approach to estimating paddy rice water demand in Hwanghaenam-do, North Korea. Agric. Water Manage. 89: 185-198, doi: 10.1016/j.agwat. 2007.01.009.

Korea Meteorological Administration (KMA). 2010. Understanding of Climate Change and Application of Climate Change Scenarios. National Institute of Meteorological Research: Seoul (in Korean).

Korea Rural Economic Institute (KREI). 1996. Classification of agricultural region and potential agricultural production in North Korea. Rural Development Administration, Seoul (in Korean, with English abstract)

Levene H. 1960. Robust test for equality of variances. In Contributions to Probability and Statistics: Essays in Honour of Harold Hotelling, Olkin I, Ghurye SG, Hoeffding W, Madow WG, Mann HB (eds). Stanford University Press: Stanford, CA.

Nam WH, Hong EM, Choi JY. 2015. Has climate change already affected the spatial distribution and temporal trends of reference evapotranspiration in South Korea? Agric. Water Manage. 150: 129-138, doi: 10.1016/j.agwat.2014.11.019.

Penalba OC, Robledo FA. 2010. Spatial and temporal variability of the frequency of extreme daily rainfall regime in the La Plata Basin during the $20^{\text {th }}$ century. Clim. Change 98: 531-550, doi: 10.1007/s10584-009-9744-6.

Portmann RW, Solomon S, Hegerl GC. 2008. Spatial and seasonal patterns in climate change, temperatures, and precipitation across the United States. Proc. Natl. Acad. Sci. USA 106: 7324-7329, doi: 10.1073/pnas.0808533106.

Raziei T, Daryabari J, Bordi I, Modarres R, Pereira LS. 2014. Spatial patterns and temporal trends of daily precipitation indices in Iran. Clim. Change 124: 239-253, doi: 10.1007/s10584-014-1096-1. 
Reiter A, Weidinger R, Mauser W. 2012. Recent climate change at the upper Danube - a temporal and spatial analysis of temperature and precipitation time series. Clim. Change 111: 665-696, doi: 10.1007/s10584-011-0173-y.

Shi W, Tao F, Liu J, Xu X, Kuang W, Dong J, Shi X. 2014. Has climate change driven spatio-temporal changes of cropland in northern China since the 1970s? Clim. Change 124: 163-177, doi: 10.1007/s 10584-014-1088-1.

Stephenson DB. 1997. Correlation of spatial climate/weather maps and the advantages of using the Mahalanobis metric in predictions. Tellus 49A: 513-527, doi: 10.1034/j.1600-0870.1997. t01-4-00001.x. 